\title{
ARTIFICIAL CULTIVATION OF A NOVEL WILD STRAIN OF LEPISTA SORDIDA (SOWERBY) PAT FROM SOUTH WEST CHINA
}

\author{
De Xu*, Hui Zhao, Biao Li, Chuanqi Sun, Zhide Wang and JIE Ma \\ Dazhou Academy of Agricultural Sciences, Dazhou, China
}

Keywords: Cultivation, Lepista sordida, Morphological description, Molecular identification

\begin{abstract}
A novel wild strain of Lepista sordida mushroom was collected from a soybean field in Liujiaba at Dazhou district of south western area of China in 2015.The morphological description and molecular identification were conducted to confirm the species. In the present study, optimization was carried out from mycelial growth and fruit body production. For DAAS-E70, the best growth rate was obtained using yeast malt extract, $\mathrm{pH} 6.0$ and temperature $25^{\circ} \mathrm{C}$. The wheat grain mushroom spawn was used for upscaling of the mycelium to be used for fruiting body production. In the field experiments, the average biological efficiency of DAAS-E70 was higher than that of Jilin-1, in which, DAAS-E70 accounting for $41.22 \%$ of the average biological efficiency, while the Jilin-1 was $35.02 \%$. The stable biological efficiency of DAAS-E70 in different environments and seasons showed that the DAAS-E70 could be used for its commercial cultivation and could provide a new reference for its artificial domestication.
\end{abstract}

\section{Introduction}

Lepista, belonging to Tricholomataceae is widely distributed in Asia, America, Europe, Australia and Africa (Pringle and Vellinga 2006, Davis et al. 2012, Alvarado et al. 2015, Elgharabawy et al. 2017, Thongbai et al. 2017). Recent analyses suggested that the genus Lepista is polyphyletic including $L$. nuda, L. sordida and $L$. saeva as well as species of Clitocybe (Alvarado et al. 2015). Bio-active compounds from Lepista sordida was found to have anticancer, antimicrobial, and antitumor properties to humans (Mazur et al. 1996, Miao et al. 2013) and Zhong et al. 2013). The important polysaccharides could be used as a potential natural antitumor drug in human beings. Besides, further studies should be conducted to discover other biologically active compounds from fruiting bodies of Lepista sordida. Hence, it is necessary to conduct the artificial cultivation of Lepista sordida.

Lepista sordida is characterized by a deep lilac or lilac-brown pileus color, from which it is difficult to distinguish from the well-known violet, highly praised edible fungus $L$. nuda as well as the morphologically similar ectomycorrhizal fungus Cortinarius violaceus (L.) Gray. Hence, molecular techniques such as ribosomal RNA gene sequencing had been developed for their identification (Stott et al. 2005).

Recently, great efforts have been made to master its artificial domestication and cultivation of L. sordida in China, and in the past decade some progress has been seen. However, the yields have been relatively low (Tian et al. 2003, Li et al. 2014). Thus, the wild-grown L. sordida is available only in high-class restaurants. Tian et al. (2003) proposed the fermentation cultivation and clinker cultivation and explained $19.9 \%$ of the highest biological efficiency, in which, clinker cultivation biological efficiency was higher than that of fermentation cultivation. Lun (2014) explained $17.38 \%$ of the biological efficiency. As a result it is hard to conduct its commercial cultivation.

*Author for correspondence: <549286017@qq.com>. 
The purposes of the present study were to investigate the taxonomy of this fungus through morphology and molecular similarity and to determine optimal cultivation practices for the wild strain.

\section{Materials and Methods}

The fruit-bodies were collected from Dazhou, Sichuan provinces, southwest China during the rainy seasons from September, 2015. The specimens were dried at $45^{\circ} \mathrm{C}$ and kept in zip-lock plastic bags containing dehydrated silica gel. All dried wild type fruit bodies were preserved in the Herbarium of Dazhou Academy of Agricultural Sciences (DAAS) and marked as DAAS-E70. The strain Jilin-1, derived from Jilin provinces, was used for filed experiments as control.

Pure cultures were aseptically isolated on to potato dextrose agar (PDA) medium and incubated at $25^{\circ} \mathrm{C}$ in a darkroom.

Macro-morphological features were described from fresh specimens which were photographed using a Cannon 600D digital camera. The slides were observed and photographed. Measurements of basidiospores were taken using objective micrometer.

Genomic DNA was extracted from the fresh fruiting body and purified by the cationic detergent cetyl-trimethylammonium bromide (CTAB) method. The oligonucleotide primers (ITS1:5'-TCCGTAGGTGAACCTGCGG-3' and ITS4:5'-TCCTCCGCTTATTGATATGC-3') were used for amplification and the PCR amplifications were performed in ABI9700 thermal cyclers. The PCR mixture with a total volume of $25 \mu \mathrm{l}$ and contained $0.5 \mu \mathrm{l}$ of each primer, $0.5 \mu \mathrm{l}$ template (20 50 ng), $2.5 \mu \mathrm{l} 10 \times$ Taqbuffer $\left(\mathrm{Mg}^{2}+\right.$ plus $), 0.5 \mu \mathrm{dNTP}(2.5 \mathrm{mM})$, and $0.5 \mu \mathrm{l} \mathrm{T}$ aq DNA polymerase (Tiangen Biotech, Beijing Co. Ltd.). Thermal condition was performed with initial denaturation at $94^{\circ} \mathrm{C}$ for $4 \mathrm{~min}$, followed by 35 cycles at $94^{\circ} \mathrm{C}$ for $45 \mathrm{~s}, 55^{\circ} \mathrm{C}$ for $45 \mathrm{~s}$ and $72^{\circ} \mathrm{C}$ for 1 min, then final extension at $72^{\circ} \mathrm{C}$ for $10 \mathrm{~min}$. PCR products were analyzed and separated on 1.0 $1.5 \%(\mathrm{w} / \mathrm{v})$ agarose gels, stained with ethidium bromide, and visualized using UV light. The expected PCR products were purified using the San Prep Column DNA Gel Extraction Kit (Shanghai Biological Technology Co., Ltd). Obtained flanking internal transcribed spacers (ITS) nucleotide sequences were subjected to a BLAST search against the NCBI database (http://www.ncbi.nlm.nih.gov/) to match the best similarities with other related ITSs on database.

Three different media culture were used for optimizing mycelial growth rates, including compost potato dextrose agar (CPDA), potato dextrose agar (PDA) and yeast malt extract agar (YMA). After incubation for 7 days of pure culture on PDA, the growing edge of each colony was cut out by using a cork-borer and placed on the center of each medium in $9 \mathrm{~cm}$ Petri dishes. Five replicates of each medium were incubated at $25^{\circ} \mathrm{C}$ for 20 days in a darkroom. Mycelial growth was measured and its characteristics were recorded. The mycelial density was determined by following the scoring system of Kadiri (1998). Mycelial disks from the colony edge of 8-day-old Petridish cultures were transferred to YMA medium to obtain the optimal temperature for mycelial growth. Five different temperatures $\left(15,20,25,30\right.$ and $\left.35^{\circ} \mathrm{C}\right)$ were used for optimizing mycelial growth rates. The medium and temperature exhibiting the highest growth rate were used to evaluate the optimal $\mathrm{pH}$. The $\mathrm{pH}$ was adjusted to 5,6,7 and 8 with $\mathrm{HCl}$ and $\mathrm{NaOH}$ and measured by using a digital $\mathrm{pH}$ meter before autoclaving. The colony diameter for each $\mathrm{pH}$ was recorded.

Three different media i.e., wheat compost, corncob and cow manure compost were used for spawn culture. The mycelium growth from the edge of colonies actively growing on PDA medium was aseptically cut with an 8-mm cork-borer and transferred on to the surface of the spawn substrate. Three replicates of each inoculated spawn substrate were incubated at $25^{\circ} \mathrm{C}$ until the mycelium colonized the substrate completely. The linear mycelium length was measured $(\mathrm{cm})$ after 7 days and successively in a 4-day period until the mycelium filled the jars. 
The compost medium for field study was prepared with Corncob as the main substrate mixed with other ingredients using a modified protocol based on a previous study, in which, cow manure $(40 \%)$, calcium carbonate $(2 \%)$, calcium sulfate $(2 \%)$, rice husk $(6 \%)$, and a sufficient amount of water to provide 60 - 65\% moisture (Zhou et al. 2017). The compost substrate was pasteurized and allowed to cool down to room temperature before inoculating the spawn at $30 \mathrm{~g}$ of colonized grain/ $/ \mathrm{kg}$ compost. The $120 \mathrm{~kg}$ of the spawn/compost substrate mixture was placed in filed $(10 \times$ $0.8 \times 0.15 \mathrm{~m}$ ) and incubated at $22 \sim 25^{\circ} \mathrm{C}$ with relative humidity at $60-65 \%$ for the beginning of colonization. During the time taken for spawn running in the compost media, the surface was covered with plastic film to avoid drying and insect contaminations. The completely colonized compost was covered with sand soil to a $2-3 \mathrm{~cm}$ thickness and covered with plastic to avoid drying. Once mycelium colonized the entire casing ayer, the casing was uncovered at $12 \sim 23^{\circ} \mathrm{C}$ and $90-98 \%$ humidity was maintained by spraying water. The field experiments were conducted at Liujiaba, China, during the autumn of 2018 and spring of 2019, respectively. Five replications were used in the experiment and the fresh weight of fruiting bodies was recorded.

Results are expressed in a one-way analysis of variance (ANOVA) analysis the mycelia growth values for growth rate, medium type, temperature and $\mathrm{pH}$ optimization, and spawn substrate were compared to obtain a mean separation using Tukey's test $(p=0.05)$, followed by multiple comparisons using IBM SPSS Statistics software19.

\section{Results and Discussion}

Pileus: small to medium-sized, $2.0-7.8 \mathrm{~cm}$ wide, initially convex then applanate to slightly concave, flattening out or developing a central depression at maturity with a slight umbo and a wavy margin, ranging in color from deep lilac to purple together with hygrophanous (Fig. 1a,b). Lamellae: light purple, crowded (Fig. 1c). Basidiospores: $(4.0-5.0) \times(5.0-7.0) \mu \mathrm{m}$, ellipsoid, colorless, hyaline, thin- walled, finely verrucose with small apiculus (Fig. 1d). Mycelium: colorless, hyaline, same size with clamp connection (Fig. 1e). Stipe: $4.5-9.0 \mathrm{~cm}$ long, deep lilac longitudinally striate, downy and fibrillose white at base with no ring (Fig. 1f). Taste: pleasant. Odor: strong fruity. Habitat: mixed lawn or wood land and usually in areas with accumulations of decomposing leaf litter. Distribution: widely distributed in Asia, America, Europe, Australia and Africa.

The ITS nucleotide sequences in the NCBI data base (http://www.ncbi.nlm.nih.gov/) revealed that the most similar sequences were from $L$. sordida KF874612 from China at $99.71 \%$ similarity, 85\% query cover; with KR154993 from India at $99.13 \%$ similarity, $85 \%$ query cover; with KJ137272 from USA at $99.56 \%$ similarity, $84 \%$ query cover. The sequence of the DAAS-E70 was deposited in the NCBI data base under accession number MT994848.

Effects of three agar media on mycelial growth, biomass and density are presented in Table 1. The radial mycelial growth observed on YMA was highly significantly faster than those of CPDA and PDA as well as the biomass and density. Hence, it may be concluded that the YMA was the suitable agar media for mycelial growth of DAAS-E70. The color of mycelium growing on CPDA was purple-white, while it appeared dark purple on PDA and YMA.

Effects of five different temperature and four different $\mathrm{pH}$ on mycelial growth biomass and density were shown in Table 2. The results illustrated that the mycelia grew well in range of 20 to $30^{\circ} \mathrm{C}, 25^{\circ} \mathrm{C}$ was the optimum.

The optimal $\mathrm{pH}$ for mycelial growth of DAAS-E70 was in 6.0. Effects of different spawn cultures on mycelial growth were presented in Table 3 . The best growth and density occurred on wheat compost. 

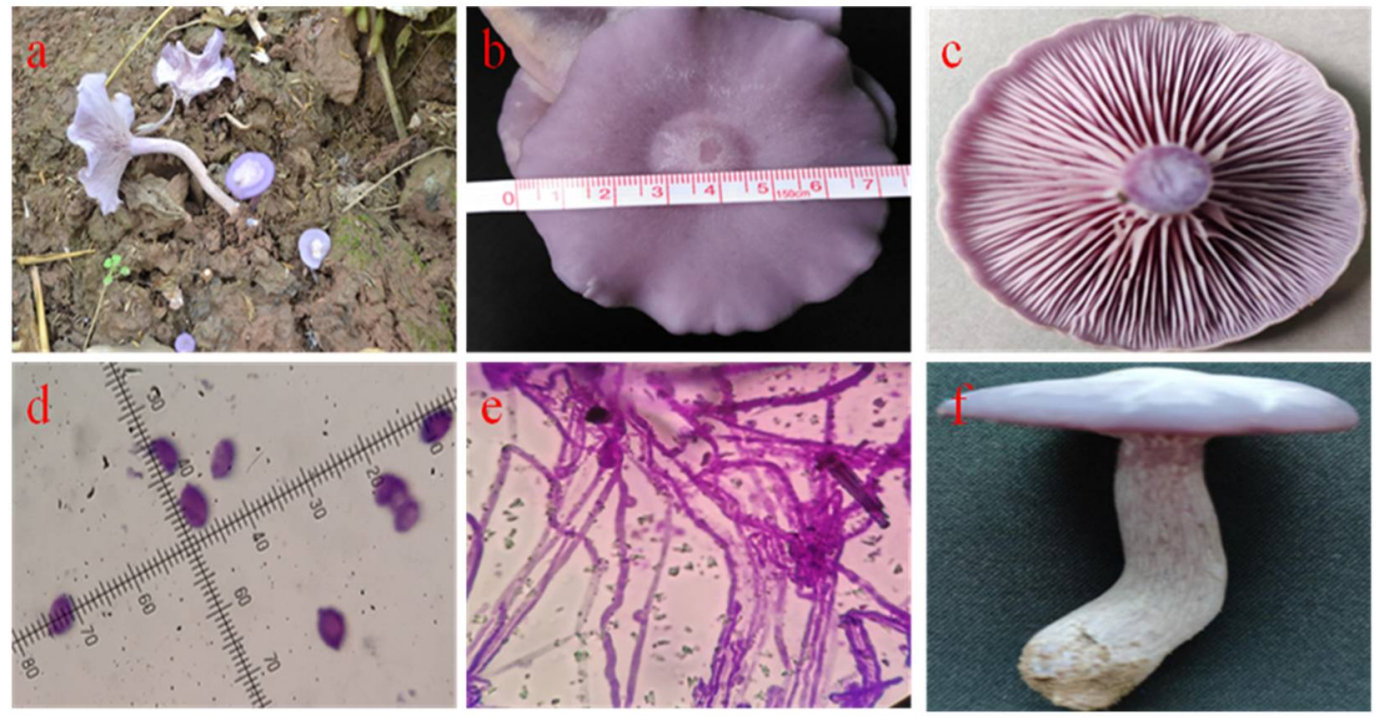

Fig.1. Characteristics of Lepista sordida wild strain. a. Basidiomata. b. Pileus. c. Lamellae. d. Basidiospores. e. Mycelium. f. Stipe.

Table 1. Effects of culture media on mycelial growth, biomass, density of DAAS-E70.

\begin{tabular}{lccc}
\hline Culture media & Colony diameter $(\mathrm{cm})$ & Biomass $(\mathrm{mg})$ & Density \\
\hline PDA & $4.98 \pm 0.03 \mathrm{c}$ & $78.17 \pm 0.35 \mathrm{c}$ & +++ \\
YMA & $5.87 \pm 0.02 \mathrm{a}$ & $88.43 \pm 0.50 \mathrm{a}$ & +++++ \\
CPDA & $5.32 \pm 0.03 \mathrm{~b}$ & $83.25 \pm 0.73 \mathrm{~b}$ & ++++ \\
\hline
\end{tabular}

values with the same letter are not significantly different (Tukey, $\mathrm{p} \leq 0.05) .+,++,+++,++++$ and +++++ represent very scanty, scanty, moderate, abundant and very abundant respectively.

Table 2. Effect of different temperature and pH on mycelial growth biomass and density of DAAS-E70.

\begin{tabular}{cccccccc}
\hline $\begin{array}{c}\text { Temp. } \\
\left({ }^{\circ} \mathrm{C}\right)\end{array}$ & $\begin{array}{c}\text { Mycelium growth } \\
(\mathrm{mm} / \mathrm{d})\end{array}$ & $\begin{array}{c}\text { Biomass } \\
(\mathrm{mg})\end{array}$ & Density & $\mathrm{pH}$ & $\begin{array}{c}\text { Colony diameter } \\
(\mathrm{cm})\end{array}$ & Biomass $(\mathrm{mg})$ & Density \\
\hline 15 & $3.39 \pm 0.06 \mathrm{~d}$ & $63.14 \pm 0.67 \mathrm{c}$ & ++ & 5 & $4.17 \pm 0.05 \mathrm{c}$ & $69.81 \pm 0.42 \mathrm{~b}$ & +++ \\
20 & $4.96 \pm 0.07 \mathrm{~b}$ & $85.55 \pm 0.28 \mathrm{~b}$ & +++ & 6 & $5.68 \pm 0.02 \mathrm{a}$ & $87.78 \pm 0.38 \mathrm{a}$ & ++++ \\
25 & $5.74 \pm 0.09 \mathrm{a}$ & $88.58 \pm 0.56 \mathrm{a}$ & ++++ & 7 & $5.63 \pm 0.06 \mathrm{~b}$ & $87.08 \pm 0.13 \mathrm{a}$ & ++++ \\
30 & $4.56 \pm 0.11 \mathrm{c}$ & $84.23 \pm 0.47 \mathrm{~b}$ & +++ & 8 & $3.26 \pm 0.05 \mathrm{~d}$ & $51.07 \pm 0.22 \mathrm{c}$ & ++ \\
35 & $2.79 \pm 0.13 \mathrm{e}$ & $43.26 \pm 1.07 \mathrm{~d}$ & + & & & & \\
\hline
\end{tabular}

At approximately 20 days, mycelium colonized the entire compost media and casing layer. Mature fruiting bodies formed on the surface of the casing layer after 30 days at $12-23^{\circ} \mathrm{C}$. Additional flushes followed after 37 43 days and the last flush was produced at 48 50 days. In the present study, the filed results showed that the average field biological efficiency of DAAS- 
E70 was higher (41.22\% than that of Jilin-1 (35.02\%) (Table 4). The stable biological efficiency of DAAS-E70 in different environments and seasons showed that the DAAS-E70 could be used for its commercial cultivation and could provide a new reference for its artificial domestication.

Table 3. Effect of different culture media on mycelial growth and density of DAAS-E70.

\begin{tabular}{lcc}
\hline Culture media & Mycelium growth $(\mathrm{Mm} / \mathrm{D})$ & Density \\
\hline Wheat compost & $5.59 \pm 0.03 \mathrm{a}$ & ++++ \\
Corn cob compost & $2.83 \pm 0.06 \mathrm{c}$ & +++ \\
Cow manure compost & $5.57 \pm 0.01 \mathrm{~b}$ & +++ \\
\hline
\end{tabular}

Table 4. Biological efficiency of two strains in different seasons.

\begin{tabular}{cccccc}
\hline \multirow{2}{*}{ Strain ID } & \multicolumn{2}{c}{ Autumn 2018 $(\%)$} & \multicolumn{2}{c}{ Spring 2019 $(\%)$} & $\begin{array}{c}\text { Average } \\
\text { biological }\end{array}$ \\
\cline { 2 - 4 } & Liujiaba & Fangdou & Liujiaba & Fangdou & efficiency (\%) \\
\hline DAAS-E70 & 43.22 & 42.13 & 40.12 & 39.41 & 41.22 \\
Jilin-1 & 35.31 & 35.82 & 35.23 & 33.71 & 35.02 \\
\hline
\end{tabular}

The present study showed that L. sordida collected from Dazhou, Sichuan provinces, southwest China could be domesticated and brought into cultivation successfully and, therefore, has a high potential for commercial production, readily available agricultural products and waste materials were tested as spawn substrates to make cultivation possible at a relatively low cost. The results showed that the wheat grain was the best spawn substrate for the cultivation of L. sordida. However, considering the high costs, the sorghum grains with the low costs and good availability should be used for commercial spawns production according to Thongbai et al. (2017). Additionally, compared with broken grains, high-quality spawn substrates with undamaged cereal grains and proper sterilization procedures are critical for producing L. sordida mushrooms (Narh et al. 2011).

\section{Acknowledgments}

The authors would like to thank the Major Research Projects of Sichuan (2019YFN0130) for providing financial support, as well as the key Research Projects of National modern agricultural industrial technology system Sichuan edible fungi team (sccxtd-2020-07).

\section{References}

Alvarado P, Moreno G, Vizzini A, Consiglio G, Manjón JL and Setti L 2015. Atractosporocybe, Leucocybe and Rhizocybe: three new clitocyboidgenera in the tricholomatoid clade (Agaricales) with notes on Clitocybe and Lepista. Mycologia 107: 123-136.

Davis RM, Sommer R and Menge JA 2012. Field guide to mushrooms of Western North America. University of California Press, Berkely, Los Angeles, California. pp. 246-247.

Elgharabawy HM, El-Sayed AK and El-Fallal A 2017. First record of Lepista sordida (schumach) singer in Eastern North Africa. The $7^{\text {th }}$ Inter. Conf. Plant \& Microbial. Biotech. and their role in the development of the society. pp. 111-118. 
Kadiri M 1998. Spawn and fruit body production of Pleurotus sajor-caju in Abeokuta, Nigeria. Niger J. Bot. 11:125-131.

Lun ZM 2014. Artificial cultivation and polysaccharide structure analysis of lepista sordida. Northeast Forestry University, pp.41-43.

Li WS, Lue YS, Wu TY, Tsai SJ and Chen MH 2014. Domestication of native Lepista soridida (Fr.) Singerin Taiwan. J. Taiwan Agric. Res. 63(3): 216-224.

Mazur X, Becker U, Anke T and Sterner O 1996. Two new bioactive diterpenes from Lepista sordida. Phytochemistry 43: 405-407.

Miao S, Mao X, Pei R, Miao S, Xiang C, Lva Y, Yang X, Sun J, Jia S and Liu Y 2013. Lepista sordida polysaccharide induces apoptosis of Hep-2 cancer cells via mitochondrial pathway. Int. J. Biol. Macromo. 16: 97-101.

Narh DL, Obodai M, Baka D and Dzomeku M 2011. The efficacy of sorghum and millet grains in spawn production and carpophores formation of Pleurotus ostreatus (Jacq. Ex. Fr) Kummer. Int. Food Res. J. 18: $1143-1148$.

Pringle A and Vellinga EC 2006. Last Chance to Know? Using literature to explore the biogeography and invasion biology of the death cap mushroom Amanita phalloides (Vaill. ex Fr.: Fr.) Link. Biological Invasions 8(5): 1131-1144.

Stott K, Desmerger C and Holford P 2005. Relationship among Lepista species determined by CAPS and RAPD. Mycological Res. 109(2): 205-211.

Tian GT, Yang QF and Xu XZ 2003. A study on the domestication cultivation of lepista sordida. Acta Edulis Fungi 10(1): 52-56

Thongbai B, Wittstein K, Richter C, Miller SL, Hyde KD, Thongklang N, Klomklung N, Chukeatirote E and Stadler M 2017. Successful cultivation of a valuable wild strain of Lepista Sordida from Thailand. Mycological Progress 16(4): 1-13.

Zhou HM, Zhang YZ, Chai HM, Zhang XL, Luo WD, Liu DQ and Ji LJ 2017. Biological characteristics and cultivation of a wild-type Lepista sordida Strain. Acta Edulis Fungi 24(1): 39-44.

Zhong W, Liu N, Xie Y, Zhao Y, Song X and Zhong W 2013. Antioxidant and anti-aging activities of mycelia polysaccharides from Lepista sordida. Int. J. Biol. Macromol. 60: 355-359.

(Manuscript received on 19 May, 2021; revised on 13 September, 2021) 